\title{
Ring Slotted Circularly Polarized U-Shaped Printed Monopole Antenna for Various Wireless Applications
}

\author{
K.G. Jangid ${ }^{1}$, P.K.Jain ${ }^{2}$, B. R. Sharma ${ }^{3}$, V.K.Saxena ${ }^{2}$, V.S.Kulhar ${ }^{1}$, D. Bhatnagar ${ }^{2}$ \\ ${ }^{1}$ Department of Physics, Manipal University, Jaipur, India-303007 \\ ${ }^{2}$ Microwave Lab, Department of Physics, Jaipur, India-302004 \\ ${ }^{3}$ Department Department of Physics, SKITM\&G, Jaipur, India-302017 \\ *corresponding author, E-mail: kgkris1980@rediffmail.com
}

\begin{abstract}
In this communication, the design and performance of micro strip line feed U-shaped printed monopole antenna for Bluetooth/WI-MAX/WLAN communications systems is reported. The proposed monopole antenna has an eight shaped slot on the patch and an eight shaped ring structure in the ground with a metallic reflector beneath the ground plane. The CST Microwave Studio 2014 used for the simulation analysis of antennas while measurements performed by applying Vector Network Analyzer (R\&SZVA 40). This radiating structure provides triple broad impedance bandwidths, i.e. $265 \mathrm{MHz}$ (in $2.280 \mathrm{GHz}$ to $2.545 \mathrm{GHz}$ frequency range), $116 \mathrm{MHz}$ (in $2.660 \mathrm{GHz}$ to $2.776 \mathrm{GHz}$ frequency range) \& $2.12 \mathrm{GHz}$ (in $3.83 \mathrm{GHz}$ to $5.956 \mathrm{GHz}$ frequency range), wider $3 \mathrm{~dB}$ axial ratio bandwidth $1.33 \mathrm{GHz}$ (in $4.69 \mathrm{GHz}$ to $6.02 \mathrm{GHz}$ range), nearly flat gain (with maximum gain close to $5.56(\mathrm{dBi})$ and good radiation patterns in the desired frequency range. This antenna may be a useful structure for $2.45 \mathrm{GHz}$ Bluetooth communication band as well as in WLAN \& WI-MAX communications bands.
\end{abstract}

\section{Introduction}

The rapid advancements in the wireless communication systems, especially in the field of high data transfer, have awakened more interest of the scientific community towards the performance enrichment of the wireless antennas. These antennas must perform well for application in communication systems, including WLAN applications specifically $802.11 \mathrm{~b}$ and $802.11 \mathrm{~g}$ for $2.4 \mathrm{GHz}$ communication systems, $802.11 \mathrm{a}$ standard for the $5 \mathrm{GHz}$ communication system, high-speed 802.11 for operation in both $2.4 \mathrm{GHz}$ and $5.0 \mathrm{GHz}$ bands as well as in WI-MAX applications [1-2]. Circularly polarized planar monopole patch antennas are found suitable for these bands due to their flexibility in orientation, easy feeding, low profile structure and low fabrication cost of mass production [3]. Looking these advantages, extensive efforts have been made by researchers to improve the inherent limitations of planar antennas [4-17]. These include design of fork like monopole with a wide slot ground [4], wideband E-shaped micro strip patch antenna for $5-6 \mathrm{GHz}$ wireless communications systems [5], miniaturized U-slot patch antenna with enhanced bandwidth [6], Wideband omni directional monopole antenna [7], flared monopole antenna with a V-shaped sleeve [8], L-shaped printed monopole antenna with wide impedance bandwidth [9] etc. A trapezoid conductor backed plane applied to get a dual band antenna incubating WLAN and WI-MAX in [10]. A tripleband monopole patch covering the WLAN \& WI-MAX communication systems obtained by using electric-LC (ELC) and EBG structures [11]. A new design of coaxial probe feed dual layer circular patch antenna presented in [12]. With the substantial bonding between two patches, a wide bandwidth approx. $25 \%$ obtained. Most of these references have larger patch size, but the compactness of structure is the main requirement in modern wireless communication systems. A very compact asymmetric coplanar strip fed monopole structure for dual frequency bands presented in [13]. Another compact design presented in [14] which has L-shaped radiating element, a modified inverted-F-shaped stub and a $\mathrm{C}$-shaped parasitic radiating element for WLAN and WI-MAX application. Triple bands obtained by applying a pair of inverted-L slots etched on the ground plane and a split-ring resonator (SRR) in [15]. A tapered printed structure attached to U-slot reported in [16] to achieve WLAN dual frequency bands. In [17], a directional dual band performance obtained by tuning the lengths of the inner symmetrical trapezoidal slots and the outer trapezoidal arms.

The main objectives of this communication to obtain a single structure which has compactness, high gain, multiple operation bands and circular polarization. Rectangular and circular configurations are the most common configuration. In this communication, a new U-shaped design has offered which has a compact size compared to other configurations and provides circular polarization that desires in several wireless communications. Broadband performance and circular polarization have achieved through U-shaped monopole structure with an eight shape ring slot in the patch geometry and an eight shape ring in the ground plane. The gain of the antenna has improved through application of a metallic reflector placed beneath the radiating structure. The CST Microwave Studio 2014 has used for the simulation analysis of antennas while measurement has performed by 
using Vector Network Analyzer (R\&S-ZVA 40) \& RF signal generator.

\section{Antenna Design and Analysis}

The geometrical model of a U-shaped patch antenna having dimension $\mathrm{L} \times \mathrm{W}$ is depicted in Fig. 1 (a). This antenna is designed on a glass epoxy FR-4 substrate having relative permittivity $\left(\varepsilon_{\mathrm{r}}\right)$ of 4.4 , thickness of the patch $(\mathrm{t})$ $0.0035 \mathrm{~mm}$, substrate height (h) $1.59 \mathrm{~mm}$ and loss tangent 0.025. A microstrip line feeding structure with length $\mathrm{L}_{\mathrm{f}}$ and width $\mathrm{W}_{\mathrm{f}}$ is employed to feed this geometry. The optimized dimensions of the proposed antenna are provided in Table 1.

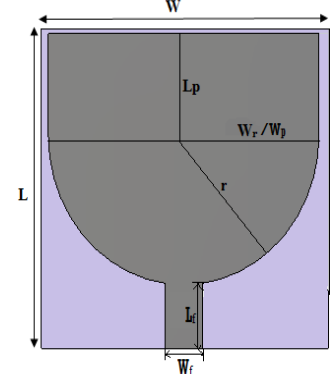

(a)

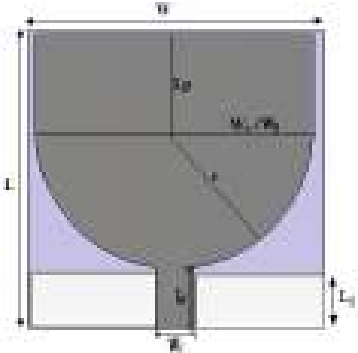

(c)

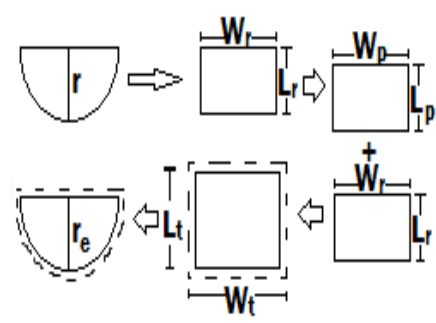

(b)

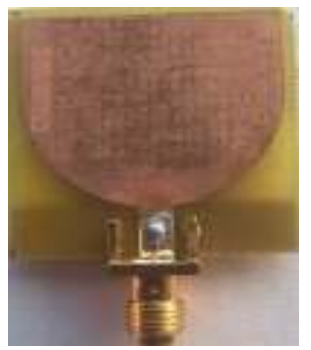

(d)
Figure 1: (a) Geometry of U-shaped planar antenna having finite ground, (b) Modeling details of patch geometry, (c) Geometry of U-shaped Monopole patch antenna, (d) Prototype of U-shaped monopole patch antenna

Table 1: Optimized dimensions of proposed antenna.

\begin{tabular}{cc}
\hline Dimension of proposed antenna & Value[in mm] \\
\hline $\begin{array}{c}\text { Size of substrate/ground }(\mathrm{L} \mathrm{X} \mathrm{W)} \\
\text { Dimensions of feed line }\left(\mathrm{L}_{\mathrm{f}} \times \mathrm{W}_{\mathrm{f}}\right)\end{array}$ & $60 \times 30$ \\
$\begin{array}{c}\text { Radius of semi-circular part of the } \\
\text { patch }(\mathrm{r})\end{array}$ & 14.8 \\
$\begin{array}{c}\text { Dimensions of rectangle part of the } \\
\text { patch }\left(\mathrm{L}_{\mathrm{p}} \mathrm{X} \mathrm{\textrm {W } _ { \mathrm { p } }}\right)\end{array}$ & $9.5 \times 28$ \\
\hline
\end{tabular}

The resonance frequency of this antenna is then estimated through mathematical modeling of patch geometry. The radiating patch is considered a combination of a semicircle of radius ' $r$ ' $\&$ diameter $W_{r}=2 r$ and a rectangular part having dimensions $\mathrm{L}_{\mathrm{p}} \times \mathrm{W}_{\mathrm{p}}$ where $\mathrm{W}_{\mathrm{p}} \approx \mathrm{W}_{\mathrm{r}}$. Following [18], the semicircular part of the considered microstrip patch (SCMSP) is then modeled by assuming it equivalent to a rectangular microstrip patch (RMSP) as shown in Fig. 1(b). The length $L_{r}$ of the RMSP is equal to $\Pi r$ / 4 and width $\mathrm{W}_{\mathrm{r}}$ of the RMSP is equal to the diameter (2r) of the SCMSP. After converting this SCMSP into RMSP, we have added the rectangle part $\left(\mathrm{L}_{\mathrm{p}} \times \mathrm{W}_{\mathrm{p}}\right)$ in it. The culminating part of the radiating structure is then considered equivalent to a rectangle having dimensions $\mathrm{L}_{t} \times \mathrm{W}_{\mathrm{t}}$ where $\mathrm{L}_{\mathrm{t}}=\mathrm{L}_{\mathrm{r}}+\mathrm{L}_{\mathrm{p}}$ and $\mathrm{W}_{\mathrm{t}}=\mathrm{W}_{\mathrm{p}}=\mathrm{W}_{\mathrm{r}}$. Due to fringing effect, the effective dielectric constant and the edge extensions for all four sides of the RMSA has calculated by using equation (1) \& (2) [19].

$$
\varepsilon_{e f f}=\varepsilon_{r}-\left[\left(\varepsilon_{r}-\varepsilon_{e f f}(0)\right) /(1+P)\right.
$$

Where $\varepsilon_{\text {eff }}(0)$ is the static effective dielectric constant, and is given as

$$
\begin{aligned}
& \varepsilon_{e f f}(0)=1 / 2\left[\left(\varepsilon_{r}+1+\left(\varepsilon_{r}-1\right) G\right)\right. \\
& G=\left(1+\frac{10 h}{L_{t}}\right)^{-A B}-\left[\left(\frac{\ln 4}{\pi}\right)\left(t .\left(L_{t} h\right)^{-1 / 2}\right]\right. \\
& A=1+\frac{1}{49} \ln \left\{\frac{\left(L_{t} / h\right)^{4}+\frac{L_{t}{ }^{2}}{(52 h)^{2}}}{\left(L_{t} / h\right)^{4}+0.432}\right\} \\
& +\frac{1}{18.7} \ln \left\{1+\left(L_{t} / 18.1 h\right)^{3}\right\} \\
& B=0.564 \exp \left\{\frac{-0.2}{\varepsilon_{r}+0.3}\right\} \\
& P=P_{A} P_{B}\left[\left(0.1844+P_{c} P_{d}\right) f_{n}\right]^{1.5763} \\
& P_{A}=0.27488+\left[0.6315+\left\{\frac{0.525}{\left(1+0.0157 f_{n}\right)^{20}}\right\}\right] U \\
& -0.065683 \exp (-8.7513 U) \\
& P_{B}=0.33622\left[1-\exp \left(-0.03442 \varepsilon_{r}\right)\right] \\
& P_{c}=0.0363 \exp (-4.6 U)\left[1-\exp \left\{-\left(\frac{f_{n}}{38.7}\right)^{4.97}\right\}\right] \\
& P_{D}=1+2.751\left[1-\exp \left\{-\left(\frac{\varepsilon_{r}}{15.916}\right)^{8}\right\}\right] \\
& f_{n}=47.713 k h, \text { where } k=\frac{2 \pi}{\lambda} \\
& U=\frac{2\left[L_{t}+\left(d L_{t}-L_{t}\right) / \varepsilon_{r}\right]}{h} \\
& d L_{t}=L_{t}+\frac{t}{\pi}\left[1+\ln \left\{\frac{4}{\sqrt{\frac{t}{h}}}+\frac{\left(\frac{1}{\pi}\right)^{2}}{\left(\frac{L_{t}}{t}+1\right)^{2}}\right\}\right]
\end{aligned}
$$

The edge extension for the length of this combined radiating structure has dictated through equation (2)

$$
\Delta L_{t}=h \frac{\xi_{1} \xi_{2} \xi_{3} \xi_{5}}{\xi_{4}}
$$

Where $\quad \xi_{1}=0.434907 \frac{\varepsilon_{e f f}(f)^{0.81}+0.26}{\varepsilon_{e f f}(f)^{0.81}-0.189} \frac{\left(L_{t} / h\right)^{0.80 .85441}+0.236}{\left(L_{t} / h\right)^{0.80 .85441}+0.87}$

$$
\begin{gathered}
\xi_{2}=1+\frac{\left(L_{t} / h\right)^{0.371}}{2.358 \varepsilon_{r}+1} \\
\xi_{3}=1+\frac{0.5274 \arctan \left\{0.067\left(L_{t} / h\right)^{1.9413 / \xi_{2}}\right.}{\varepsilon_{e f f}(f)^{0.81}}
\end{gathered}
$$




$$
\begin{aligned}
\xi_{4}=1+ & 0.03770 \arctan \left\{0.067\left(\frac{L_{t}}{h}\right)^{1.456}\right. \\
& \times\left[6-5 \exp \left\{0.036\left(1-\varepsilon_{r}\right)\right\}\right] \\
\xi_{5}=1 & -0.218 \exp \left(-7.5 \frac{L_{t}}{h}\right)
\end{aligned}
$$

Similarly we also get the edge extension $\left(\Delta W_{t}\right)$ for the width of this radiating structure.

By using equation (1) and (2)

$$
\mathrm{L}_{\text {teff }}=\mathrm{L}_{\mathrm{t}}+\Delta L_{t} \quad \text { and } \quad \mathrm{W}_{\text {teff }}=\mathrm{W}_{\mathrm{t}}+\Delta W_{t}
$$

To find out the resonant frequency of different modes we applied a method that is used in [20]. According to effective rectangular geometry is again considered equivalent to a semi circle having effective radius $r_{e}$ where

$$
r_{e}=\sqrt{\frac{\mathrm{L}_{\text {teff }} \mathrm{W}_{\text {teff }}}{\pi}}
$$

Following [20-21], the resonance frequency of proposed geometry may be obtained as:

$$
\mathrm{f}_{\mathrm{r}}=\frac{\mathrm{k}_{\mathrm{nm}} \mathrm{c}}{2 \pi \mathrm{r}_{\mathrm{e}} \sqrt{\varepsilon_{\mathrm{eff}}}}
$$

Here $k_{n m}$ is the $m_{t h}$ zero root derivative of Bessel function of order $\mathrm{n} ; \varepsilon_{\text {eff }}$ is the effective dielectric constant of the substrate material and $\mathrm{c}$ is the velocity of light.

Table 2: Different calculated parameters of U-shaped

\begin{tabular}{cc}
\multicolumn{2}{c}{ antenna } \\
\hline Calculated Parameter & Value \\
\hline $\mathrm{L}_{\text {teff }}$ & $21.34 \mathrm{~mm}$ \\
$\mathrm{~W}_{\text {teff }}$ & $28.82 \mathrm{~mm}$ \\
$\mathrm{r}_{\mathrm{e}}$ & $13.99 \mathrm{~mm}$ \\
$\varepsilon_{\text {eff }}$ & 4.07 \\
$\mathrm{k}_{\mathrm{nm}}\left(\mathrm{TM}_{110} \& \mathrm{TM}_{210}\right)$ & $1.84118 \& 3.05424$ \\
Resonant Frequency for & $3.115 \mathrm{GHz} \& 5.167 \mathrm{GHz}$ \\
$\mathrm{TM}_{110} \& \mathrm{TM}_{210}$ & \\
\hline
\end{tabular}

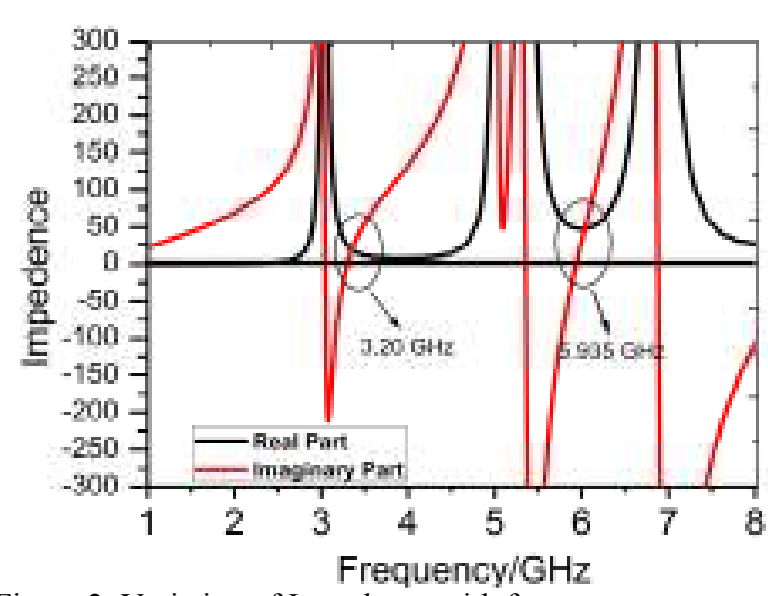

Figure 2: Variation of Impedance with frequency.

The simulation analysis carried out through CST Microwave Studio simulator 2014, reveals that the resonant frequencies of these modes (where imaginary part of input impedance is zero) are $3.20 \mathrm{GHz}$ and $5.935 \mathrm{GHz}$ respectively. The modeled and simulated resonance frequencies of antenna are in good agreement in $\mathrm{TM}_{110}$ mode. A nice matching of the antenna with feed line has realized at frequency $5.93 \mathrm{GHz}$ as shown in Fig. 3. The simulated impedance bandwidth of considered U-shaped antenna with the finite ground plane is nearly $2 \%$ with respect to central frequency $5.942 \mathrm{GHz}$ and average gain with obtaining bandwidth is close to $1 \mathrm{dBi}$. This impedance bandwidth and gain value is significantly low; hence antenna has modified in steps.

\subsection{Wideband circularly polarized antenna}

In the next step of modification, the size of considered finite ground having dimensions $\mathrm{L} \times \mathrm{W}$ is reduced to $\left(\mathrm{L}_{\mathrm{g}} \times \mathrm{W}\right)$ after several optimizations. The design of this antenna has shown in Fig. 1 (c) while the developed prototype has shown in Fig. 1 (d). The simulation analysis of this monopole antenna reveals that it is effectively operating at frequencies $3.53 \mathrm{GHz}$ and $5.25 \mathrm{GHz}$ as shown in Fig. 2. The simulated impedance bandwidth of the antenna is close to $3.05 \mathrm{GHz}$ or $67 \%$ with respect to central frequency $4.53 \mathrm{GHz}$. The presence of higher order modes in planar monopole antenna contributes to the enhancement of impedance bandwidth that is also realized in the considered geometry. The measured results of proposed geometry are in excellent agreement with simulation results as shown in Fig. 3. The measured resonance frequencies of antenna are $3.48 \mathrm{GHz}$ and $5.34 \mathrm{GHz}$ while the measured impedance bandwidth is $2.97 \mathrm{GHz}$ or $\sim 66 \%$ with respect to central frequency $4.487 \mathrm{GHz}$. More alterations in the patch and ground plane are carried out to further improve the performance of the antenna. The geometry of this circularly polarized wideband antenna is next modified in two steps. In the first step, a horizontal eight shaped ring slot in patch geometry having outer \& inner radius $R_{1}$ and $R_{2}$ respectively with slot thickness $\mathrm{W}_{1}$ is introduced. Thereafter, retaining this ring slot on patch geometry, a horizontal eight shaped ring having outer \& inner radius $\mathrm{R}_{3}$ and $\mathrm{R}_{4}$ respectively with slot thickness $\mathrm{W}_{2}$ also introduced in ground plane. The front and back views of modified geometrical models of the proposed monopole patch antenna are presented in Figs. 4 (a) and 4 (b) while these views of developed prototype are shown in Figs. 4 (c) \& 4 (d) respectively. The design details are given in Table 3 .

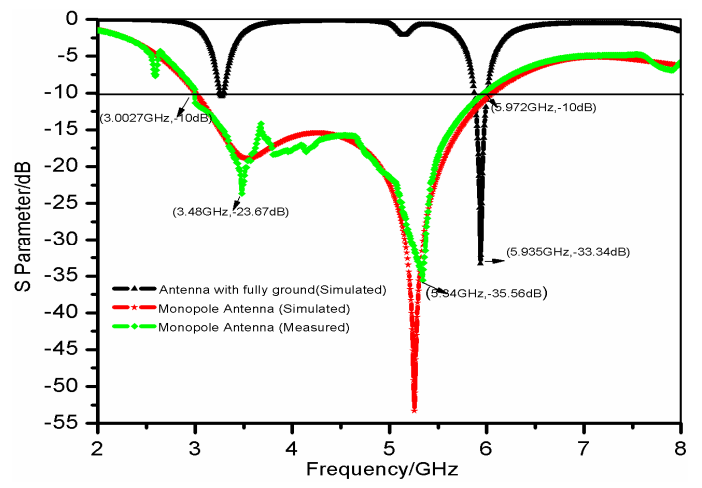

Figure 3: Measured/Simulated reflection coefficient of antenna with frequency in different cases. 


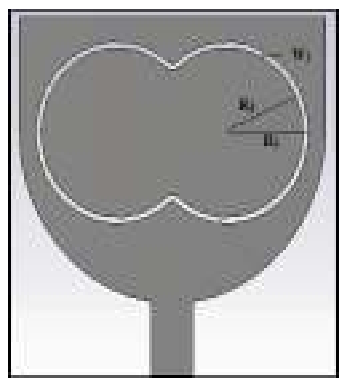

(a)

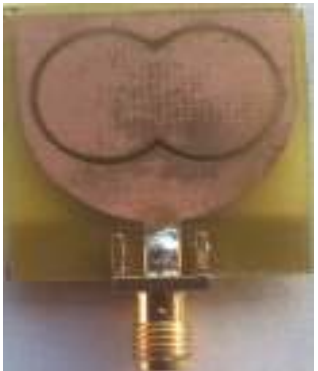

(c)

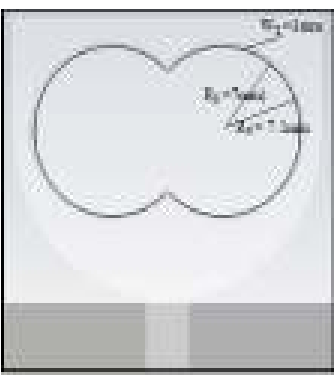

(b)

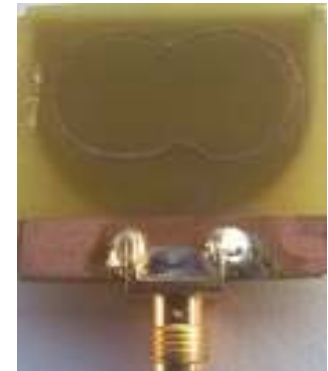

(d)
Figure 4: Geometrical model and prototype of modified monopole patch antenna of $U$ shaped planar antenna.

Table 3: Optimized dimensions of proposed antenna.

\begin{tabular}{cc}
\hline Geometrical parameters & Value(in mm) \\
\hline Inner radius of slot $\left(\mathrm{R}_{2}\right)$ & $7 \mathrm{~mm}$ \\
outer radius of slot $\left(\mathrm{R}_{1}\right)$ & $7.5 \mathrm{~mm}$ \\
Thickness of introduced slot $\mathrm{W}_{1}$ & $0.5 \mathrm{~mm}$ \\
Inner radius of ring $\left(\mathrm{R}_{3}\right)$ & $7.0 \mathrm{~mm}$ \\
outer radius of ring $\left(\mathrm{R}_{4}\right)$ & $7.1 \mathrm{~mm}$ \\
Thickness of introduced ring $\mathrm{W}_{2}$ & $0.1 \mathrm{~mm}$ \\
\hline
\end{tabular}

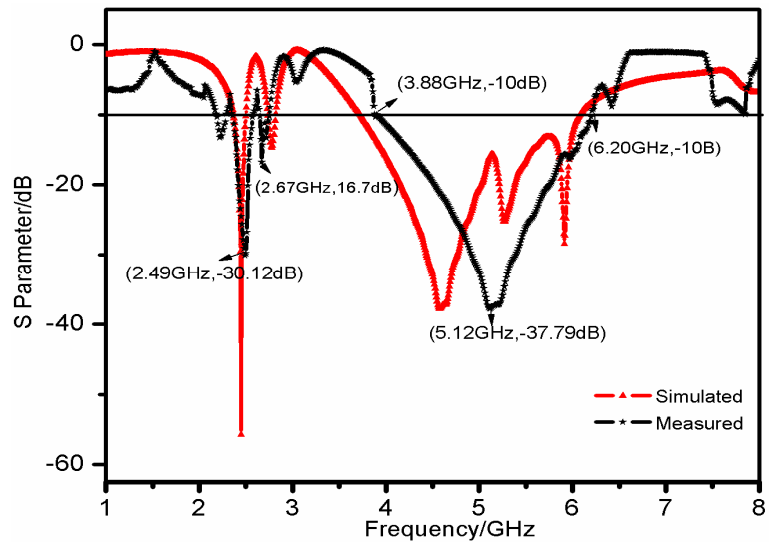

Figure 5: Measured/Simulated variation of reflection coefficient of antenna with frequency

A comparison between simulated and measured reflection coefficient variations for this antenna having a slot in the patch and ring in the ground plane has shown in Fig. 5. A nice agreement for simulated and measured result at frequencies $2.49 \mathrm{GHz}, 2.67 \mathrm{GHz} \& 5.12 \mathrm{GHz}$ has realized. The frequencies $4.57 \mathrm{GHz}$ and $5.91 \mathrm{GHz}$ for which nice matching is realized through simulation cannot be achieved through measurements. The involved design complications limit is perhaps responsible for the disagreement. The simulated and measured impedance bandwidths of antenna are $2.35 \mathrm{GHz}$ and $2.32 \mathrm{GHz}$ respectively which are in good agreement. Fig. 6 illustrates the simulated surface current distribution of the antenna at $2.45 \mathrm{GHz}, 2.77 \mathrm{GHz}$ and $5.27 \mathrm{GHz}$. In each case, the maximum current density concentrates mainly on the eight shaped slot on the patch, hence it is responsible for the improved performance of the antenna.

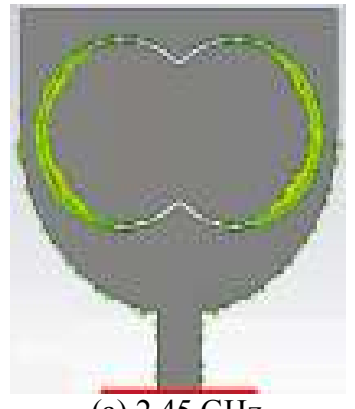

(a) $2.45 \mathrm{GHz}$

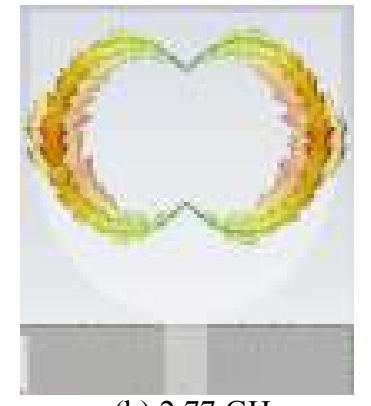

(b) $2.77 \mathrm{GHz}$

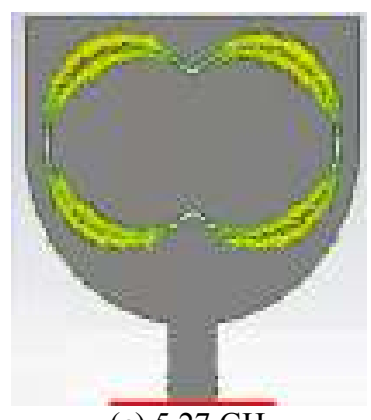

(c) $5.27 \mathrm{GHz}$

Figure 6: Simulated surface current distribution of the proposed antenna at various frequencies.

The simulated gain of antenna at frequencies $2.45 \mathrm{GHz}$ and $2.77 \mathrm{GHz}$ are $1.24 \mathrm{dBi}$ and $0.60 \mathrm{dBi}$ respectively, while in the frequency range of interest $(3.70 \mathrm{GHz}$ to $6.07 \mathrm{GHz})$. The gain values of present structure are low and almost constant. A comparison between simulated variations of axial ratio in two cases has shown in Fig. 7. The testing for circular polarization has performed at several $(\theta, \phi)$ values and finally with $\theta=75^{\circ}$ and $\phi=85^{\circ}$, the best performance (maximum axial ratio bandwidth) of the antenna has obtained. In the first case when patch has a ring shaped slot only, the axial ratio bandwidth has achieved from $5.09 \mathrm{GHz}$ to $5.93 \mathrm{GHz}$, while in the second case, when patch has a ring shaped slot and ground has a ring, the axial ratio bandwidth has obtained from $4.69 \mathrm{GHz}$ to $6.02 \mathrm{GHz}$. In this way, the simulated axial ratio bandwidth which has $840 \mathrm{MHz}$ or $15 \%$ with respect to central frequency $5.51 \mathrm{GHz}$ in the first case has increased to $1.33 \mathrm{GHz}$ or $24.84 \%$ with respect to central frequency $5.35 \mathrm{GHz}$ on the introduction of a ring in the ground plane. The two dimensional simulated and measured E \& H-planes radiations patterns of proposed structure have obtained at two frequencies $2.45 \mathrm{GHz}$ and $5.12 \mathrm{GHz}$. The simulated and measured $\mathrm{E} \& \mathrm{H}$ Plane radiation patterns are in excellent agreement as depicted in Fig. 8. The E-plane patterns of both frequencies are almost omnidirectional and 
resembles with those of a monopole antenna. The direction of maximum radiation is normal to patch antenna, but more power has directed in backward direction. The H-plane patterns have a dumbbell shape formation with almost equal radiations in forward and backward directions. The obtained $3 \mathrm{~dB}$ beam widths are close to $78^{\circ} \& 62^{\circ}$ degree respectively at these frequencies.

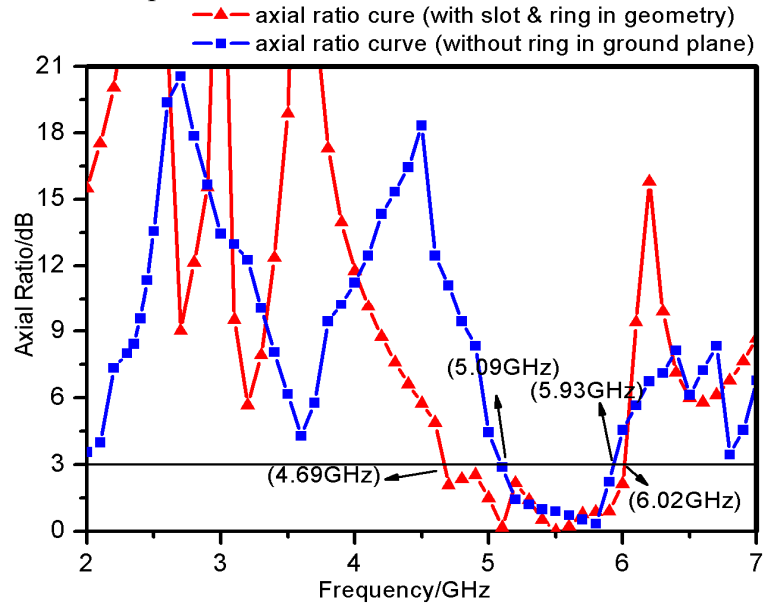

Figure 7: Simulated axial ratio variation with frequency
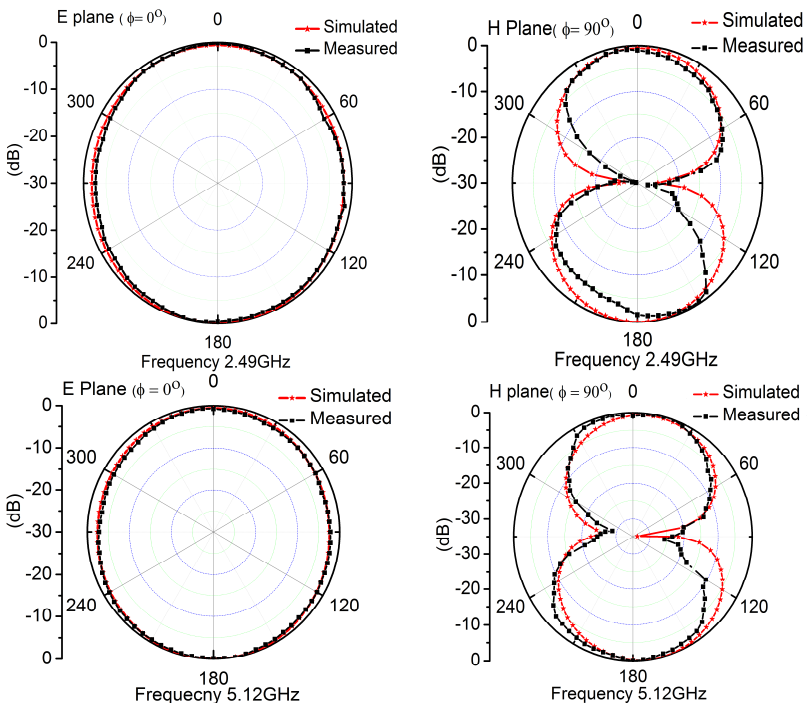

Figure 8: $\mathrm{E} \& \mathrm{H}$ plane radiation pattern of the proposed antenna at different frequencies.

\subsection{Proposed antenna structure with reflector}

The main limitation of this monopole structure is its low gain and poor directivity as almost equal radiations are realized both in forward and backward directions. To overcome this limitation, a thin rectangular metal sheet having dimensions $60 \mathrm{~mm}$ x $60 \mathrm{~mm}$ has placed as a reflector at proper place $(\mathrm{H}=24 \mathrm{~mm})$ beneath the proposed antenna structure. The distance of reflector from the antenna has chosen to satisfy the condition of constructive interference of radiations. The proposed monopole antenna with reflector has shown in Fig. 9 (a) while developed prototype has shown in Fig. 9 (b).

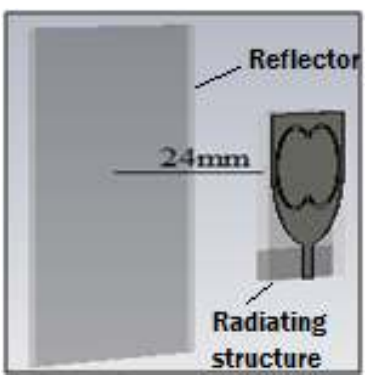

(a)

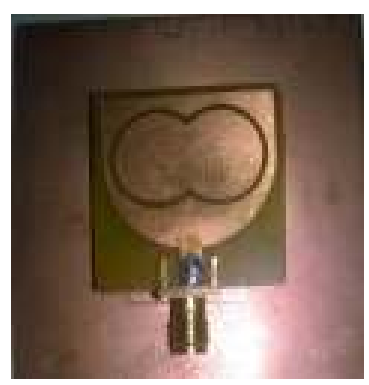

(b)
Figure 9: Geometrical \& fabricated prototype proposed patch antenna with reflector.

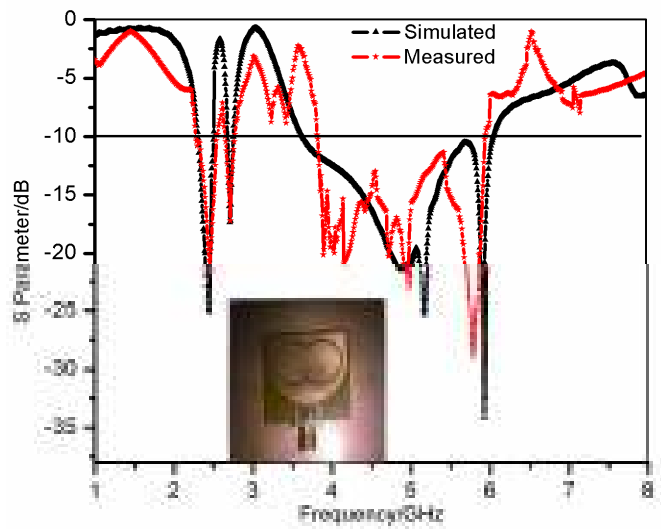

Figure 10: Variation of reflection coefficient with frequency of proposed antenna with reflector.

The simulated and measured variations of reflection coefficient with frequency are demonstrated in Fig. 10. The measured results present triple band behavior of the antenna as it shows impedance bandwidth of $265 \mathrm{MHz}$ in the frequency range $2.280 \mathrm{GHz}$ to $2.545 \mathrm{GHz}, 116 \mathrm{MHz}$ in the frequency range $2.660 \mathrm{GHz}$ to $2.776 \mathrm{GHz} \& 2.12 \mathrm{GHz}$ in the frequency range $3.83 \mathrm{GHz}$ to $5.956 \mathrm{GHz}$. These frequency bands are useful for Bluetooth and WLAN/WIMAX communication systems. The marginal difference between simulated and measured results has observed due to the complications involved in design \& fabrication of antenna and measurement surroundings. When the backward directed wave radiated from the antenna falls on the reflector, it gets reflected. If the distance between the antenna and reflector is selected in such a way that the reflected waves from the reflector and radiated waves from the antenna are in phase, then the directivity and hence the gain of the antenna improves. The measured and simulated far field radiation patterns of antenna in $\mathrm{E}\left(\phi=0^{\circ}\right)$ and $\mathrm{H}\left(\phi=90^{\circ}\right)$ planes at frequencies $2.45 \mathrm{GHz}, 5.17 \mathrm{GHz}$ and $5.79 \mathrm{GHz}$ are shown in Fig. 11, which indicates that radiation patterns are now more directed in the front direction. The measured radiation pattern is fully unidirectional in lower and middle frequency range. A comparison of gain performance of antenna with and without metallic reflector is also shown in Fig. 12. With introduction of metallic reflector, the gain of the antenna at frequency $2.45 \mathrm{GHz}$ is $4.90 \mathrm{dBi}$, at frequency $2.71 \mathrm{GHz}$ is $4.94 \mathrm{dBi}$, and in the frequency range extended from 3.83 $\mathrm{GHz}$ to $5.956 \mathrm{GHz}$, it is variable from $4.4 \mathrm{dBi}$ to $4.9 \mathrm{dBi}$. 
These gain values are almost four times higher than those realized in the previous sections. The maximum gain of the antenna in the present case is close to $5.56 \mathrm{dBi}$ at $2.42 \mathrm{GHz}$. The obtained results suggest that on the introduction of a reflector, gain and directivity of the antenna are improved considerably without any compromise with bandwidth and circular polarization results.
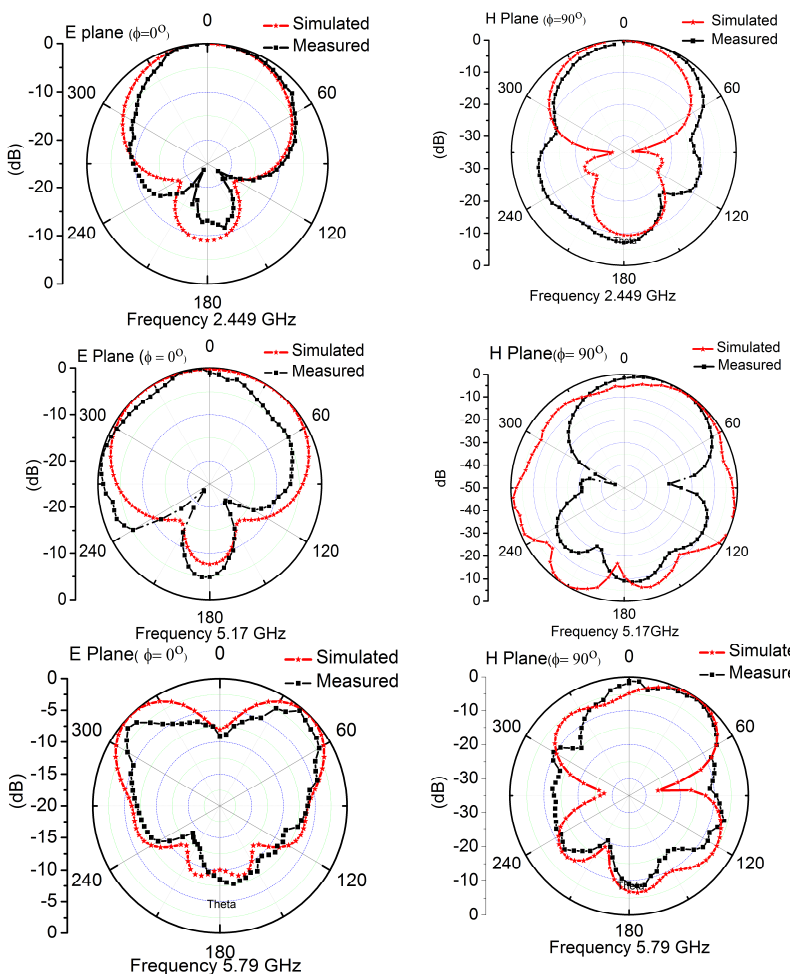

Frequency $5.17 \mathrm{GHz}$

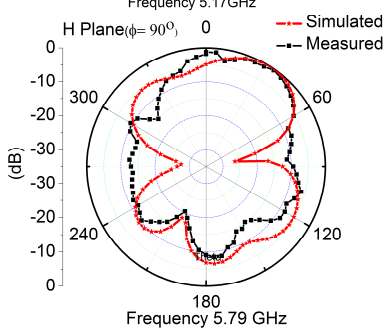

Figure 11: Simulated/Measured 2D radiation pattern in E \& $\mathrm{H}$ planes at various resonance frequencies

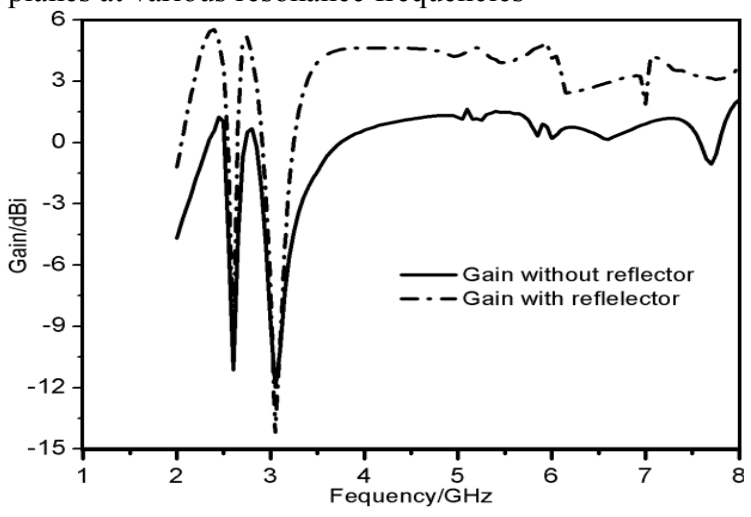

Figure 12: Simulated variation of gain with frequency of proposed antenna with reflector.

\section{Discussion}

The comparison of performance of different recent antenna designs with proposed antenna is given in Table 3 which demonstrates that the proposed antenna structure has a compact size and high gain characteristics.
Table 4: Comparisons of performance of the Proposed Antenna with other multi band designed antenna

\begin{tabular}{|c|c|c|c|}
\hline Ref. & $\operatorname{Size}\left(\mathrm{mm}^{2}\right)$ & $\begin{array}{c}\text { Operating } \\
\text { Frequency Band } \\
(\mathrm{GHz})\end{array}$ & $\begin{array}{l}\text { Avg. Peak } \\
\text { Gain(dBi) }\end{array}$ \\
\hline $\begin{array}{l}\text { Proposed } \\
\text { Antenna }\end{array}$ & $30 \times 30$ & $\begin{array}{l}2.280 \text { to } 2.545 \\
2.660 \text { to } 2.77 \\
3.83 \text { to } 5.95 \text {. }\end{array}$ & 5.56 \\
\hline 22 & $35 \times 30$ & $\begin{array}{c}2.4 / 5.2 / 5.8 \mathrm{GHz} \\
\text { WLAN Bands } \\
\text { 3.5/5.5GHz } \\
\text { WiMAX Bands }\end{array}$ & 4.1 \\
\hline 23 & $38 \times 20$ & $\begin{array}{c}\text { 2.4/5.8 GHz } \\
\text { WLAN Bands } \\
\text { 3.5 WiMAX } \\
\text { Bands }\end{array}$ & 3.1 \\
\hline 24 & $35 \times 25$ & $\begin{array}{c}2.4 / 5.2 / 5.8 \mathrm{GHz} \\
\text { WLAN Bands } \\
3.5 / 5.5 \mathrm{GHz} \\
\text { WiMAX Bands }\end{array}$ & 2.4 \\
\hline $\begin{array}{l}25 \\
26\end{array}$ & $\begin{array}{c}16 \times 70 \\
28 \times 58.6\end{array}$ & $\begin{array}{l}2.1 \mathrm{GHz}-6.0 \mathrm{GHz} \\
1.9 \mathrm{GHz}-5.2 \mathrm{GHz}\end{array}$ & ---- \\
\hline 27 & $39 \times 46$ & $\begin{array}{c}2.27 \mathrm{GHz}-4.64 \\
\mathrm{GHz}\end{array}$ & 2.85 \\
\hline 28 & $33 \times 2$ & $2.45 / 5.8 \mathrm{GHz}$ & 3.27 \\
\hline
\end{tabular}

\section{Conclusions}

Proposed U-shaped monopole planar antenna having eight shaped ring slot in patch and eight shaped ring in ground plane with metallic reflector beneath the ground plane provide triple band performance. The impedance bandwidths in these bands extend from $2.280 \mathrm{GHz}$ to $2.545 \mathrm{GHz}, 2.660$ $\mathrm{GHz}$ to $2.776 \mathrm{GHz}$ and $3.83 \mathrm{GHz}$ to $5.956 \mathrm{GHz}$ respectively. Desired flat gain (close to $5 \mathrm{dBi}$ ), better directivity and good radiation patterns in the desired frequency range are also realized with proposed geometry. The maximum gain of the antenna is close to $5.56 \mathrm{dBi}$ at $2.4 \mathrm{GHz}$. This antenna may be proved a useful structure for modern wireless communication systems, including in devices like Bluetooth, WLAN, WI-MAX and lower band of UWB communication systems.

\section{Acknowledgements}

Authors are thankful to DEIT, New Delhi for the financial support provided for the present work. Authors also extend their sincere thanks to Mr. V.V. Srinivasan, ISAC, and Bangalore for his valuable help in this work.

\section{References}

[1] E. Danielyan, IEEE 802.11, The Internet Protocol Journal 5: No. 1, March 2002. 
[2] J. Pinalo, K. Pentikousis, Mobile WiMAX, The Internet Protocol Journal 11: No. 2, June 2008.

[3] I.-J.Bahl, P. Bhartia, Microstrip Antennas, Artech House, Norwood, 1980.

[4] G. Liu, Y. Liu, S. Gong, Compact tri-band wide-slot monopole antenna with dual-ring resonator for WLAN/WiMAX applications, Microw. Opt. Technol. Lett. 58: 1097-1101, 2016. doi:10.1002/mop.29759.

[5] B.-K. Ang, B.-K. Chung, A wideband E-shaped microstrip patch antenna for 5-6 GHz wireless communications, Progress In Electromagnetics Research 75: 397-407, 2007.

[6] G.-F. Khodae, J. Nourinia, C. Ghobadi, A practical miniaturized U-slot patch antenna with enhanced bandwidth, Progress In Electromagnetics Research B 3: 47-62, 2008.

[7] Y.-T. Liu, C.-W. Su, Wideband omnidirectional operation monopole antenna, Progress In Electromagnetics Research Letters 1: 255-261, 2008.

[8] G. Augustin, P.-C. Bybi, V.-P. Sarin, P. Mohanan, C.K. Aanandan, K. Vasudevan, A compact dual-band planar antenna for DCS-1900/PCS/PHS, WCDMA/IMT-2000 and WLAN applications, IEEE Antennas and Wireless Pro. Letters 7: 108-111, 2008.

[9] K.-P. Ray, S.-S. Thakur, R.A. Deshmukh, Wideband L-shaped printed monopole antenna, Int $J$ Electron Communication 66: 693-696, 2012.

[10] C.-Y. Pan, H.T. Sheng, C.-W. Shan, C. Hsiang, Dual wideband printed monopole antenna for WLAN/WiMAX application, IEEE antennas Wireless Propagation Letters 6: 149-151, 2007.

[11] K. Li, C. Zhu, L. Li, Y.-M. Cai, C.-H. Liang, Design of electrically small Meta material antenna with ELC and EBG loading, IEEE antennas Wireless Propagation Letters 12: 678-681,2013.

[12] J. Chen, J. Liu, A new broadband dual-layer monoplolar circular patch antenna with slot coupling, Microw. Opt. Technol. Lett. 59: 40-43, 2017. doi:10.1002/mop.30218.

[13] A. Sharma, R.-K. Gangwar, Compact tri-band cyclindrical dielectric resonator antenna with circular slots for wireless application, Journal of Electromagnetics Wave Applications 30: 331-340, 2016.

[14] B.-J. Wu, Q.-Y. Feng, A novel compact broadband antenna for LTE/WLAN/WiMAX applications, Progress In Electromagnetics Research Letters 59: 129-135, 2016.

[15] Y. Xu, C. Zhang, Y.-Z. Yin, Z. Yang, Compact tripleband monopole antenna with inverted-1 slots and SRR for WLAN/WiMAX applications, Progress In Electromagnetics Research Letters 55: 1-6,2015.

[16] N. Zhang, P. Li, B. Liu, X.-W. Shi, Y.J. Wang, Dualband and low cross-polarisation printed dipole antenna with L-slot and tapered structure for WLAN applications, Electron. Lett. 47: 360-361, 2011. doi:10.1049/el.2011.0104.

[17] F. Pang, J. Yin, W. Chen, J. Yang, C. Xie, X. Li, A dual-band slotted trapezoidal inverted-f antenna for indoor WLAN communications, Progress In Electromagnetics Research Letter 64: 57-63,2016.

[18] G. Kumar, K.-P. Ray, Broadband Microstrip Antennas, 74-79, Artech House, Boston, London, 2003.

[19] K.-P. Ray, G. Kumar, Determination of the resonant frequency of microstrip antennas, Microwave Optical Tech. Letters 23: 114-117, 1999.

[20] J.-A. Ansari, A. Mishra, B.-R. Vishvakarma, Half Uslot loaded semicircular disk patch antenna for GSM mobile phone and optical communications, Progress In Electromagnetics Research C 18: 31-45, 2011.

[21] L. Shen, S. Long, M. Allerding, M. Walton, Resonant frequency of circular disk printed circuit antenna, IEEE Transactions on Antennas and Propagation 25: no. 4, 595-596, 1977.

[22] W. Ren, C. Jiang, A novel design of multiband printed anchor-shaped slot antenna, Microw. Opt. Technol. Lett. 58: 521-526, 2016. doi:10.1002/mop. 29602.

[23] X. Ren, S. Gao, Y. Yin, Compact tri-band monopole antenna with hybrid strips for WLAN/WiMAX applications. Microwave and Optical Technology Letters 57: No. 1, 94-99, 2015.

[24] Y. Xu, Y.-C. Jiao, Y.-C. Luan, Compact CPW-fed printed monopole antenna with triple-band characteristics for WLAN/WiMAX applications, Electronics Letters 48: No. 24, 1519-1520, 2012.

[25] L.-M. Si, Q.-L. Zhang, W.-D. Hu, W.-H. Yu, Y.-M. Wu, X. Lv, W.-A. Zhu, Uniplanar Triple-Band Dipole Antenna Using Complementary Capacitively Loaded Loop, IEEE Trans Antennas wireless Propag Lett 14: 743-746, 2015.

[26] A.-N. Yeganeh, S.-H. Najmolhoda, S.-H. Sedighy, M.A. S. Nezhad, New compact planar wideband antenna with flat gain and good pattern stability, Microw. Opt. Technol. Lett 58: 2548-2554, 2016. doi:10.1002/mop.30092.

[27] N. Choudhary, A. Tiwari, J.-S. Saini, V.-K. Saxena, D. Bhatnagar, Planar arrangement of modified concentric rings with defected ground for mobile and wireless communication systems, Progress In Electromagnetics Research M 47, 161-169, 2016. doi:10.2528/PIERM16012401

[28] Y. Yu, J. Ni, Z. Xu, Dual-band Dipole Antenna for $2.45 \mathrm{GHz}$ and $5.8 \mathrm{GHz}$ RFID Tag Application, Advanced Electomagnetics 4(1), 31-35, 2015. 